\title{
Stakeholders Conflict and Private-Public Partnership Chain (PPPC): Supply Chain of Perishable Product
}

\author{
Mahmud Akhter Shareef \\ School of Business \& Economics, North South University, Bangladesh \\ mahmud_akh@yahoo.com \\ Yogesh K. Dwivedi \\ School of Management, Swansea University, UK \\ ykdwivedi@gmail.com \\ Jashim Uddin Ahmed \\ School of Business \& Economics, North South University, Bangladesh \\ jashim.ahmed@northsouth.edu \\ Uma Kumar \\ Sprott School of Business, Carleton University, Canada \\ umakumar@cunet.carleton.ca \\ Rafeed Mahmud \\ Ottawa University \\ mahmud.rafeed@gmail.com
}

\begin{abstract}
:
Design/methodology/approach - This study uses exploratory investigation to evaluate relations among members of the supply chain of perishable food items. In this context, it is designed to investigate the field, observe the members of the existing supply chain from rural and remote places, and capture their interviews to accomplish the objectives.

Purpose - This paper has aimed to address procurement, logistics management, inventory control, and distribution of perishable items, i.e., vegetables, fruits, flowers, and fishes during the social isolation period of the Covid-19 era to identify conflicting interests among the channel members, present inventory and information sharing scenario, and reveal organizational dispute and existence of redundant, non-essential, and corrupted members in the supply chain.

Findings - This study identified that although the supply chain of perishable food items is controlled truly by private parties, from a realistic view, the private-public partnership is essential where the government should play the coordinating role. In this context, continuous interaction, coordination, and information sharing among the members to establish an optimum and scalable network and remove any redundant nodal points is a key success factor for managing an efficient supply chain.
\end{abstract}


Research limitations/implications - Theoretical and managerial implication of this research is enormous. The existence of functional and dysfunctional conflicts in the same supply network and how it can be detrimental to the performance of the members are exposed in this study which can be an excellent source to be investigated. Practitioners and researchers can gain a greater understanding to identify the root causes of conflicts in the existing structural dynamics shedding light on organizational interactions, power, and group behavior during the Covid-19 era.

Originality/value - From the light of management and inter-organizational conflicts, this is a pioneer study that has detected the redundant channel members, their source of power, and how their removal can present an optimum channel with group coherence and synergistic interest.

Keywords: Supply chain, Stakeholder, Organizational conflict, Structural dynamics, Group dynamics, Cognitive dissonance, Private-public partnership, Power, Covid-19

Paper type: Research Paper

\section{Introduction}

Typically, the supply chain of perishable items is a complex interconnected structure where several networks representing overwhelming interactions, processes, resources, and members with conflicting interests exist (Surana et al., 2005; Ali et al., 2017; Shareef et al., 2020b). It is more critical during the social isolation period of the Covid-19 era. Since it is a close loop, structural dynamics represented by multidimensional robust parameters are interdependent (Fawcett et al., 2012; Dreyer et al., 2016; Dwivedi et al., 2018; Campos et al., 2019). This network is substantially nonlinear, members interplay among congruent or confronting organizations, and functions and structures evolve and span with different extents, scales, and drivers (Surana et al., 2005; de Brito et al., 2008; Mena et al., 2013). Consequently, understanding and analyzing any supply chain having sheer complexity from uni-dimensional interest is to some extent unrealistic and often provides misleading ideas (Surana et al., 2005; Park-Poaps \& Rees, 2010; Singh, 2011). In this context, continuous interaction, coordination, and information sharing among the members to establish the optimum and scalable network and remove any redundant nodal points from any supply chain is a key success factor for managing an efficient supply chain (Dwivedi et al., 2018; Fosso Wamba et al., 2020; Shareef et al., 2020b). Several scholarly studies of supply chain group dynamics and resilient structure (Surana et al., 2005; Li et al., 2007; Pathak et al.,2007; Sodhi et al., 2012; Dolgui et al., 2018; Dwivedi et al., 2018; Shareef et al., 2019) explained this phenomenon by describing complexity theory 'complex adaptive system' (CAS). They exhibited that CAS is a dynamical element where interconnecting nodal points of different networks, topology, and information describing the status of the stakeholders, and the network itself is rapidly changing, configuring, restructuring, and forming new relations in a nonlinear and heterogeneous fashion. As such, predicting the performance and group dynamics of this kind of supply chain is often 
critical, and the success of this supply chain depends on proper optimization of nodal points, networks, sequential interconnections, detecting redundant members, and establishing a parsimonious close loop in the light of CAS. Convergence with aligned interests and purpose is the key driver of planning and controlling an efficient supply chain having members with this kind of conflicting interests and purpose (Singh, 2011; Mena et al., 2013; Fosso Wamba et al., 2019). It is specifically important during this current pandemic caused by Covid-19 where social isolation is the only solution, so far.

Heuristically, a supply chain of perishable food items procures products and resources from rural areas, stores, processes, transports to the central location in big cities, and distributes as the forward movement (Ahmed et al., 2008; Al-Hasan et al., 2014; Fahimnia et al., 2015; Jabbour et al. 2017; Shareef et al., 2019). On the other hand, the backflow of this kind of supply chain essentially should involve demand estimation, financial transactions, and fixation of quality standards (Surana et al., 2005; Singh, 2011). At the same time, flows in both sides having group interactions include organizational cooperation, sharing information, technological coherence, balancing power to maintain the required topology in the structural dynamics of the supply chain (McLachlin and Larson, 2011; Dubey et al., 2015a; Dwivedi et al., 2018; Shareef et al., 2020a). Traditionally, in any supply chain, network members are functionally, technologically, organizationally, financially, and topologically interconnected and interdependent. However, in the supply chain of perishable food items, by definition, members are topologically connected for the movement of products; practically they maintain self-entity with autonomous functionality (Mena et al., 2013; Shareef et al. 2020b). Financial and organizational structure, technological adaptation, and logistics management are significantly diverse among the members (Daugherty et al., 1994; Dadzie et al., 2000; de Brito et al., 2008; Park-Poaps and Rees, 2010; Mena et al., 2013; Shareef et al., 2020b). Demand forecasting is not done to optimize planning and control of inventory, rather manipulate the price to deprive the less powerful channel members of their deserving share in profit (Dwivedi et al., 2018; Shareef et al., 2019). Logistics management is also aimed not to maintain cooperation among the channel members, rather establish their own unhealthy and manipulated control on the entire planning of procurement and distribution (Balcik et al., 2010; Shareef et al., 2019). Heuristically, other than a couple of powerful members in the supply networks (middlemen), the two end-members (suppliers at origin and the retailers) have no control over inventory optimization, logistics management, and structural dynamics of the network.

Coexistence and apparent cooperation for same or at least similar goal and purpose maintaining regular connections and interactions with sheer competition to snatch majority profit by depriving other members are sometimes overarching phenomena of supply network of any domestic perishable food items (Surana et al., 2005; Singh, 2011; Fawcett et al., 2012; Mena et al., 2013). However, it is often extremely complicated for any supply chain to have different members with conflicting interests which is obviously a real scenario for any supply chain engaged in managing perishable items (Mena et al., 2013; Fawcett et al., 2015; Shareef et al., 2019). Spatial, dynamic, fragility and restructuring effects in the expectation of a greater share in revenue earning are very 
profound in perishable food item procurement, inventory planning, and control, logistics management, and distribution (Kiil et al., 2018; Moazzam et al., 2018). Cooperation is often not based on the resilient structure; but rather, it is due to maintaining minimum coexistence (ParkPoaps and Rees, 2010; Mena et al., 2013). Competition is not to manage an optimum supply network; rather, it is due to securing self-position to ensure a maximum profit by depriving the other channel members during the social isolation period of the Covid-19 era (Dwivedi et al., 2018; Shareef et al., 2019).

This is the typical scenario of perishable items such as agricultural food items, fishes, fruits, and flowers (Balcik et al., 2010; Dwivedi et al., 2018; Shareef et al., 2019). Many scholarly studies (Li et al., 2007; Pathak et al., 2007; Mena et al., 2013) investigated the barriers in the functionality of the supply chain of perishable items focusing on engineering planning and control and suggested simulation models based on CAS. Several studies explored and analyzed the unexpected scenario of this kind of supply chain considering ripple effect, disruption risks, and unbalanced structural dynamics (Lewis et al., 2013; Gupta et al., 2015; Gopal and Thakkar, 2016; Dubey et al., 2017; Shareef et al., 2020a). Researchers addressed this issue from an operational management perspective and thus, focused on information sharing and organizational cooperation among the running members of any supply networks (Meso et al., 2005; Dreyer et al., 2016; Dubey et al., 2018a; 2020). However, hardly any scholarly studies are engaged to unfold the root causes of inefficiencies and conflicts among the members focusing on the presence of excessive and redundant channel entities (Dubey and Gunasekaran, 2015c; Hughes et al., 2019; Hong et al., 2020; Shareef et al., 2020b). Without deliberating over the entire network of procurement-to-distribution of vegetables, fruits, flowers, and fishes with a deep look into topology, functionally, and autonomous inventory control, it is not practically feasible and justified to understand the group dynamics of this kind of supply chain. Recognizing the nodal points and entities of the redundant members in this supply network who are present, capitalizing the major share of profit, it is obvious that their presence is entirely not essential, and specifically, they are the obstacle to developing an efficient supply chain (Singh, 2011; Mena et al., 2013; Shareef et al., 2020b). Therefore, any intended investigation should be done from the perspective of organizational context focusing on planning, control, and cooperation during the social isolation period of the Covid-19 era.

At present, due to the strict implementation of lockdown and social isolation, the supply chain of perishable food items are severely disrupted (Cranfield, 2020; Robertson, 2020). Procurement, logistics management, and distribution are suffering from inefficient management, and it is further deteriorated due to the inclusion of new redundant members lengthening the cycle of procurementto-distribution (Hobbs, 2020). It is particularly obvious in the supply chain of vegetables, fruits, flowers, and fishes (Reardon et al., 2020). Although, in the developed countries, online shopping has been increased tremendously (10 to 25 percent has been increased), in the developing countries, who are primarily the suppliers of perishable food items, due to the absence of strong online platform, structural dynamics of supply networks have been disrupted (Cranfield, 2020; Mussell et al., 2020). Chang and Meyerhoefer (2020), Reardon et al. (2020) affirmed that among 
many reasons during the covid-19 period, fundamental causes of these disruptions are: organizational conflict, weaker transportation system and its management, and the presence of too many middlemen. Organizational conflict among the supply side members has been aggravated extensively in the supply network of vegetables, fruits, flowers, and fishes (Chang and Meyerhoefer, 2020; Singh et al., 2020). A strict lockdown system has forced the farmers to stay at home (Shareef et al., 2021). Utilizing the opportunity from this unorthodox problem, suburban middlemen are intervening in the network more aggressively, raising the price, to some extent 10 to 50 percent, and capturing the main profit from this network (Reardon et al., 2020; Singh et al., 2020).

From the light of management, it is essential to detect the redundant channel members, their source of power, and how their removal can present an optimum channel with group coherence and synergistic interest. This present study has addressed procurement, logistics management, inventory control, and distribution of perishable items, i.e., vegetables, fruits, flowers, and fishes in Bangladesh. Precisely, this study is engaged to identify conflicting interests among the channel members, present inventory and information sharing scenarios, and reveal organizational disputes and the existence of redundant, non-essential, and corrupted members in the supply chain. Specifically, this exploratory study has set its twofold objectives as:

1. Detect the source of conflicts and organizational topology of existing autonomous members of the supply chain of perishable items such as vegetables, fruits, flowers, and fishes during the social isolation period of the Covid-19 era

2. Design a model of supply chain considering optimum group dynamics in the light of the grounded theory of inter-organizational interactions

Therefore, the research questions of this study are to explore: i) What are the possible sources of conflict among the channel members of the supply chain of perishable items and, ii) How can the structural dynamics be improved in order to establish an effective supply chain.

The findings of this study have enormous implications for designing an efficient supply chain of perishable items such as fruits, vegetables, flowers, fishes, etc during the social isolation period of the Covid-19 era. It can address organizational conflicts, improper functionality and topology, and extremely unbalanced structural dynamics which can cause a ripple effect. It can also provide pragmatic ideas about reasons for price hiking, quality deterioration, and disproportion of profit sharing. Organizational disputes and hidden interest to deprive other stakeholders can cause broken and detached channels with apparent connections (Birkie and Trucco, 2020; Chaudhuri et al., 2020). Lacks information sharing and group coherence are also two impotent parameters to forbid the development of resilient structure and network. These issues can be resolved from this study. The entire study is engaged to explore and analyze these complex phenomena in the light of organizational conflicts, group dynamics, and the power of channel members. However, at present, due to the Covid-19 pandemic, since social isolation among organizations is extremely 
important, a robust model integrating mobile technology in the design of the supply chain can provide an effective solution.

The next section of this study has presented a literature review on the supply chain of perishable items. Then the design of this research with entire procedures is illustrated. After that, findings and interpretations of the result are presented. The next section has addressed the discussion and theory development of this study based on the findings. The managerial and theoretical implications of this study are explained in the following section. Then the conclusion of this study is stated. Finally, limitations and future research guidelines are described.

\section{Literature Review}

To resolve the research questions of this study and accomplish the objectives, this study has reviewed the literature on the supply chain of perishable food items and inter-organizational relations. To recognize the problems and develop an efficient supply chain reflecting the identified problems, this research has also explored literature on resilient supply chains and issues related to fragile structural dynamics of the supply chain of perishable products. Several researchers dealing with rural food items or perishable items procured from remote and fragmented locations revealed that these markets are at the bottom of the pyramid (Surana et al., 2005; Singh, 2011; Fawcett et al., 2012; Mena et al., 2013; Zhang et al., 2019). This scenario reflects a very scattered and unorganized connection among the stakeholders who apparently should create a network of supply structure (Zhang et al., 2019). From a theoretical point of view, these supply chains integrating supply members from rural markets are basically maintaining multi-tier networks (Singh, 2011; Mena et al., 2013). For supply network of highly perishable items, such as fish, where fishermen are presumably one of the keys and vulnerable stakeholders in this entire network, not only nodal points, network connections, and overall structural dynamics are creating complexity in planning and controlling the network, but also lack interconnectedness and inter-dependencies, selforganizational functionality, and nonaligned organizational objective are forcing the management of this type of supply chain to be nonproductive (Eisenhardt and Galunic, 2000; Choi et al., 2001; Kellen and Stefanczyk, 2002; Pathak et al., 2007). Among several issues, studies on the supply chain of food items identified that behavioral relations, manipulation, corruption, and self-centered interests are the root causes of this orthodox problem (Surana et al., 2005; Fawcett et al., 2015).

Researchers (Beamon and Kotleba, 2006; de Brito et al., 2008; Grawe, 2009; Defee et al., 2010; Mena et al., 2013; Dolgui et al., 2018; Wu and Chaipiyaphan, 2019; Messina et al., 2020) aimed to develop a resilient supply chain acknowledged several fundamental preconditions as the backbone of cost-effectiveness, efficiency, and sustainability, among which the prerequisites are: proper information sharing, strong bondage among the nodal points representing different stakeholders who are responsible for the flow of the products to the end customers, organizational cooperation, aligned objective and similar organizational functionality, and finally win-win 
relationships among the nodes. Researchers of structural dynamics (Dolgui et al., 2018) and robustness of supply chain (Surana et al., 2005; Shareef et al., 2019) and organizational functionality (Dwivedi et al., 2018) agreed that if a resilient and justified structural dynamics is not established, operation and controlling of supply chain necessarily creates several disruption risks which must propagate severe ripple effects (Sodhi et al., 2012; Dolgui et al., 2018; Cichosz et al., 2020). Changeableness and robustness in structural dynamics is the obvious nature of operating supply chain; however, fragility, noncooperation, manipulation, and introduction of redundant members to create an unexpected network in order to detach the retailer and the producer from ill motives cannot be the base of structural dynamics of any supply chain (Dreyer et al., 2016; Dubey et al., 2018a; Dwivedi et al., 2018).

It is an important issue to instigate theoretical paradigms of the efficient supply chain which can remove disruption risks inevitable in this chain and thus, ripple effect. Also, it is important to develop the base of structural dynamics which can ensure optimum connection of essential nodal points, removal of redundant nodes, and setting off a parsimonious network. This can streamline the smooth and sustainable flow of products from the producers to the end customers through distributors or wholesalers and retailers. In this connection, Rossetti and Choi (2008) and Li and Choi (2009) argued for a pragmatic solution by proposing a shortcut network starting from the supplier to the retailer, i.e., disintermediation. Researchers argued that the presence of autonomous entities is well accepted, and it cannot be a reason for misalignment (Mena et al., 2013). Particularly in rural food item supply chain, interconnectedness among members who have autonomous identity does not reflect an issue of lack of cooperation and information sharing motives (Surana et al., 2005; Singh, 2011; Fawcett et al., 2012; Mangla et al., 2018; Mena et al., 2013). However, for the fish market and agro-based supply chain, the term 'self-entity', 'detachment', and 'autonomous entities' should be interoperated from different perspectives. After procurement of fishes by the fishermen or cultivation of agricultural food items by the rural farmers, ownership of these items is transferred to several rural and urban middlemen through manipulation (Fawcett et al., 2012; Mena et al., 2013). They form the nodes of supply chain networks, although their presence is quite nonessential and they exhibit autonomous organizational entities with self-centered functionality (Shareef et al., 2020b). Consequently, they hide information, instigate detachment, and provoke non-cooperation to deprive other channel members (Cox et al., 2004).

Several researchers proposed a dyadic approach to resolve this unhealthy relationship among the members of the supply chain by proposing a network with a congruent aim, purpose, objective, and functionality (Cox et al., 2001; Mena et al., 2013; Havenga and Simpson, 2014). Critics of the dyadic approach argued that for a supply network having a simple linear relationship, knowledgebased coexistence, and cooperation is a realistic solution. However, for rural and remote-based perishable food items (for instance fish and agro-based items), where a multi-tier relationship is present and where the main source of planning and control is to ensure detachment purposefully, complexities in this supply chain should be analyzed from the view of organizational motives, 
conflicts, and display of power (Choi and $\mathrm{Wu}, 2009$ ). The arguments lie in the facts that these members can never be aligned or easily removed from this network without the intervention of external power as these redundant members in the existing supply chain capture the primary source of manipulated power (Peng et al., 2010; Wu et al., 2010; Shareef et al., 2020b). Shedding light on the theoretical development of service outsourcing (Trienekens, 2011; Zainudeen et al., 2011; Zhang et al., 2019), several studies argued that the inclusion of mobile information and communication (MIC - seamless connections through a smartphone using cross-platform voice over IP, VoIP, say Viber, WhatsApp, IMO, etc.) can be an excellent scope to gradually decrease the necessity of powerful middlemen and ensure adaptation of simple network connection from the rural or remote producers to the final retailers (Tate and Ellram, 2006; Williamson, 2008). This can also authenticate systematic structural dynamics with the simplest topology where the producers, for instance, fishermen or farmers are directly connected with the supermarket retailers. Transactional cost, lengthy lead time, redundant, and long network chain can be minimized through the seamless communication between the essential channel members through a MIC.

It is quite evident that the overall supply chain of perishable food items has not explored extensively in the light of organizational conflicts (Reardon et al., 2020; Shareef et al. 2020a). This is specifically true during the situation of social distancing (Singh et al., 2020). From the detailed literature review, it is revealed that while analyzing the supply chain of perishable agricultural food items, flowers, and fishes, researchers (Aker, 2010; Bosona and Gebresenbet, 2013; Bloom, 2015, Ali et al., 2017; Campos et al., 2019) are primarily focused on resilience, ripple effect, efficiency-related structural dynamics, and functions of intermediaries. However, several important issues like intentional organizational conflict, the presence of redundant intermediaries, and public-private partnerships were substantially ignored. From the aforementioned analysis, it is confirmed that to overcome those acute problems and create a resilient supply chain of perishable agricultural food items, flowers, and fishes, organizational conflict should be resolved by removing redundant intermediaries and ensuring government supervision. This current research can fulfill that potential research gap.

Several scholarly articles (Cranfield, 2020; Reardon et al., 2020; Robertson, 2020; Singh et al., 2020) are attempted to analyze this supply chain and performance network members during this current Covid-19 period from an operational management perspective. These studies highlighted that social isolation has detached several network members in the procurement cycle which causes prolonged distribution, price hiking, and management efficiency. However, these studies did not look at the inter-organizational conflict from the middlemen's perspective.

\section{Research Design}

This exploratory study collected data of three perishable products having an almost similar pattern of supply networks and structural dynamics in Bangladesh from field investigation. These are 
agricultural food items such as vegetables and fruits, recently familiar agro-based products such as flowers, and extremely perishable items collected from the river and sea, i.e., fishes. These three items were chosen to investigate their supply chain since these are very perishable items, similar organizational complexities exist in these value chains, and original producers (farmers and fishermen) and the end customers - all are deprived due to the presence of excessive middlemen who intervene in this market through their unorthodox and to some extent, unauthorized power. This present research design has been followed by several researchers conducting an exploratory study in the field of the supply chain (Ali et al., 2017; Arshinder and Deshmukh, 2009; Bloom, 2015; Campos et al., 2019; Dwivedi et al., 2018; Fawcett et al., 2015). To investigate the objectives, although the researchers have scope to do this in several countries like India, Bangladesh, China, England, and Canada - Bangladesh was selected due to several interrelated reasons:

- Bangladeshi market is growing very fast and it is completely an emerging economy.

- It is a developing country

- One hundred and seventy million people live in a very small area

- Supermarket retail concept is just developing in this country

- Marketing norms of these products where unethical power profoundly exists, government intervention is hardly observed.

- Exercise of power and power display is prominent and prevalent in this market

Since this study is aimed to explore sources of conflicts and organizational topology of existing autonomous members of the supply chain of perishable agro-based items and fishes, considering the aforementioned scenarios, the Bangladeshi market is an effective location to collect data and accomplish the objectives of this study.

\subsection{Methodology}

Since the study is basically dependent on scattered information of the rural fields, local markets, semi-urban marketplaces, and urban supermarket retailers, this study is designed to collect data directly from field exploration through extensive interviews and observation. It is a fundamentally qualitative study, and for this kind of investigation to get a constructive idea about existing supply networks such as structural dynamics, nodal points, their performances, roles and responsibilities, lead time, the spread of networks, logistics management, etc., the procedure designed is justified and effective (Beamon and Balcik, 2008; Balcik et al., 2010; Moazzam et al., 2018; Shareef et al., 2019).

While doing qualitative investigation through interviews and field observation, the study followed a systematic procedure to ensure the norms of an exploratory study. For justified reliability of the information and its validity as the outcome, this study designed prescribed triangulation methods with a structured sequence (Patton, 2002; Moon, 2019; Shareef et al. 2020b). It can be described in the following sequential steps: 
1. Data source triangulation: This procedure is applied to ensure variability in the selection of data sources. For this research as the exploratory study, the data source is the field players who directly constitute the nodal points of this excessive lengthy structural network. There are two certain members in this supply chain who are defined in this study as the Principal: Farmers/Fishermen located in the source (rural areas and remote places) and supermarket Retails (located in big cities, particularly in Dhaka). So, the researchers along with three research assistants discussed with three managers of three leading supermarket retailers in Dhaka, three farmers in three different rural areas (prominent for cultivation), and three fishermen in three remote riverside locations (commonplace for fishing) to identify the probable members in this supply chain, particularly the agents. Focusing on the suggestions and directives of the respondents, this study also figured out several common locations and marketplaces (nearby locations of procurement at the primary sources) where the agents (middlemen) participate in this complex supply network. Several research studies (Surana et al., 2005; Singh, 2011; Mena et al., 2013; Dwivedi et al., 2018; Kiil et al., 2018; Moazzam et al., 2018; Shareef et al., 2019) investigating agro-based and fish marketing supply chain were also reviewed in this regard.

a. Total two principals and five agents, each representing (possibly) a nodal point in the network, and three supporting service providers (cold storage, transport agency, and packaging materials) were identified who probably constitute a common supply chain of vegetables, fruits, flowers, and fishes.

b. From five possible locations, ten farmers (two from each location), ten fishermen (two from each location), fifty middlemen (agents, from each group (total five groups of middlemen), two persons from each location), and fifteen supporting service providers (one from each group - total three groups, and from each location) were interviewed. In Dhaka (Four managers from four leading retailers), Chittagong (One manager from one retailer), and Sylhet (One manager from one retailer) (three big cities and familiar for supermarket retailers), discussion and interviews were conducted with six managers from supermarket retailers.

c. In addition, five district-level government officers from five districts, nearby to the aforementioned five locations, were contacted for interviews and informal discussions to capture their valuable observations.

2. Method triangulation: Information was collected and gathered and converted into common constructs following different and distinct procedures. It was validly done following the procedures which are based on separate data collection systems like, open discussions, structured and semi-structured interviews, direct observations, and document review. Each interview and discussion were around 30 minutes long. It was almost informal. All the respondents were selected and contacted and the interviews were conducted under the guidance of local government offices (Food and agricultural department) during the first quarter of 2020 . 
3. Investigator triangulation: To capture information without any biases of investigators, the study used two researchers and three research assistants to collect data from the aforementioned five locations. In this way, the research could avoid any personal affiliation, conflicts, and interests and maintain variability in data collection through investigators.

Since, the entire information and data collection procedure followed qualitative methods, i.e., information through a verbal statement, after gathering, all the statements were rearranged, reorganized, restructured, and converted into consistent constructs following their explicit and implied meaning and significance and organizational sensemaking through cognitive schemas (based on past knowledge) and situated cognition (interpreted considering the contextual situation) (Maitlis and Christianson, 2014)). Following the principles of matrix thinking (Patton, 2002), long answers were broken down into small pieces to figure out justified common attributes systematically. In addition, the identified attributes were contrasted with published literature (Dreyer et al., 2016; Dubey et al., 2018a; Dwivedi et al., 2018; Kiil et al., 2018; Moazzam et al., 2018; Shareef et al., 2019).

Market investigation through field observations and extensive interviews of different stakeholders of existing agro-based food supply networks such as vegetables, fruits, flowers, and fishes revealed that suppliers at the origin or source (farmers/fishermen) are typically located in rural and remote areas. They bring their products to a nearby village market and sell it to a village wholesaler. The wholesaler, after collecting enough items (generally this village wholesaler has moderate knowledge about market demand and limited access to domestic market information), gathers these in a nearby semi-urban marketplace to a Mahajan/Investor/Store owner (middlemen). Then a commission agent arranges an auction. The highest bidder, typically a semi-urban wholesaler (middlemen) buys the entire item. This identification from field interviews is consistent with the findings from the literature review (Lu and Yang, 2004; Paulraj et al., 2006; Jensen, 2007; Matani, 2007; Weerakkody et al., 2007; Schipmann and Qaim, 2011; Trienekens, 2011; Bao et al., 2012; Bosona and Gebresenbet, 2013; Somashekhar et al., 2014; Bloom, 2015; Silvestre, 2015; Emana et al., 2017; Dubey et al., 2018b; Zhang et al., 2019) on the supply chain of agricultural food items, flowers, and fishes in many developing countries such China, Taiwan, India, Bangladesh, Indonesia, Sri Lanka, Brazil, Mexico, South Africa, Uganda, Tanzania, Ethiopia, Kenya, etc.

These middlemen have control over transportation, cold storage, and packaging materials. During surplus supply, they preserve excess portions in local cold storage. On the contrary, they hike prices tremendously when market demand jumps. They constantly attempt to detach the two principals (farmers/fishermen and urban supermarket retailers), block their communication, and hide information sharing. Finally, the retailers are not the loser. They compensate for the benefit by hiking the price in their retail shops, and finally, the affected entity is the end customers who pay extra. This is the typical flow for the products of agricultural food items cultivated by the farmers and fishes caught by the fishermen. On average, for vegetables, fruits, flowers, and fishes, 
there are three extra networks and nodal points in the backward linkage (local wholesaler, Semiurban Mahajan/Investor/Store owner, and semi-urban wholesaler). In addition to that, there is a typical commission agent in the marketplace who arranges an auction and gets his commission. Sometimes, the Mohajan/Investor/Store owner purchases the gathered products, but most of the time, he just takes a commission for renting his place. The semi-urban wholesaler sends the products to the big cities depending on the demand. An urban wholesaler (forward linkage) buys the products and sells them to different supermarket retailers and many small Katcha Bazar retailers. Considering this common network, in between the farmers/fishermen and the supermarket retailers, there may be five middlemen.

\section{Findings and Result Interpretation}

From the field investigations, several unique and distinctive topologies are revealed that are significantly different from the manufacturing-based supply chain. Under this study, the important issues deliberated over related to the topologies are the structure, functionality, organizational orientation, information sharing, process, planning and control, inventory forecasting and demand simulation with supply, logistics management, lead time from procurement to distribution, resources, technology, and display of power. Synthesizing the findings, the summarized identifications are categorized into three groups shown in Table 1.

\section{Table 1.}

Distinctive characteristics

of the supply chain of perishable products

\begin{tabular}{|l|l|}
\hline $\begin{array}{l}\text { Category of } \\
\text { Parameters }\end{array}$ & $\begin{array}{l}\text { Description } \\
\text { Dynamics }\end{array}$ \\
$\begin{array}{l}\text { 1. Although in principle, the collaborative supply chain reflects a closed } \\
\text { loop, this network is chained but not exactly close or connected }\end{array}$ \\
$\begin{array}{l}\text { 2. In this network, clear demarcation can be drawn by splitting the members } \\
\text { of this structure as principal (supermarket retailers and producers - } \\
\text { means farmers or fishermen) and the agents (nonessential middlemen } \\
\text { forming an open loop) }\end{array}$ \\
$\begin{array}{l}\text { 3. Due to the presence of excessive middlemen as agents, this network is } \\
\text { unreasonably longer } \\
\text { 4here are so many unsettled nodal points placed in this network to form } \\
\text { the chain from procurement to end customers } \\
\text { 5. There is no bridge or communication between the two major principles. } \\
\text { Manipulated market purposefully detaches the source suppliers from the } \\
\text { retailers } \\
\text { 6. Information sharing is barred and the entire structure is fragile. }\end{array}$
\end{tabular}




\begin{tabular}{|l|l|}
\hline Contextual & 1. In this supply chain producer or the source, the member is located in rural \\
areas (farmers) or remote locations (fishermen) \\
2. Producers/Suppliers do not have access to information about urban \\
supermarket retailers \\
3. They produce as per capacity, not knowing the demand \\
4. They have a severe lack of knowledge about the retailers' policy, quality \\
standard, and requirements \\
5. They have a lack of knowledge about the customers' demand and pricing \\
6. Power plays a major role in planning and controlling the entire supply \\
chain operation and financial management \\
7. Source principal, i.e. the suppliers of this supply chain \\
(farmers/fishermen) have no power to control any drivers of this supply \\
chain
\end{tabular}

\subsection{Existing Supply Chain}

Based on the complete qualitative study, respondents' opinions, suggestions, and the researcher's filed observations, the following supply chain can be the average representation of the present scenario of vegetable, fruit, flower, and fish related supply chain in Bangladesh (Shown in Figure 1). In the backward linkage, although the farmers/fishermen should be the main member as the supplier, sub-urban middlemen (Wholesaler) basically control the procurement and sequential distribution. Again, in the forward linkage, supermarket retailers primarily depend on the urban middlemen (Wholesaler) to settle their price. Therefore, these two agents have substantial power to control procurement, inventory management, logistics supply, and profit-sharing. Since cold storage is an ancillary member, not a direct partner of this supply network, it is stated by the dotted line in Figure 1. 


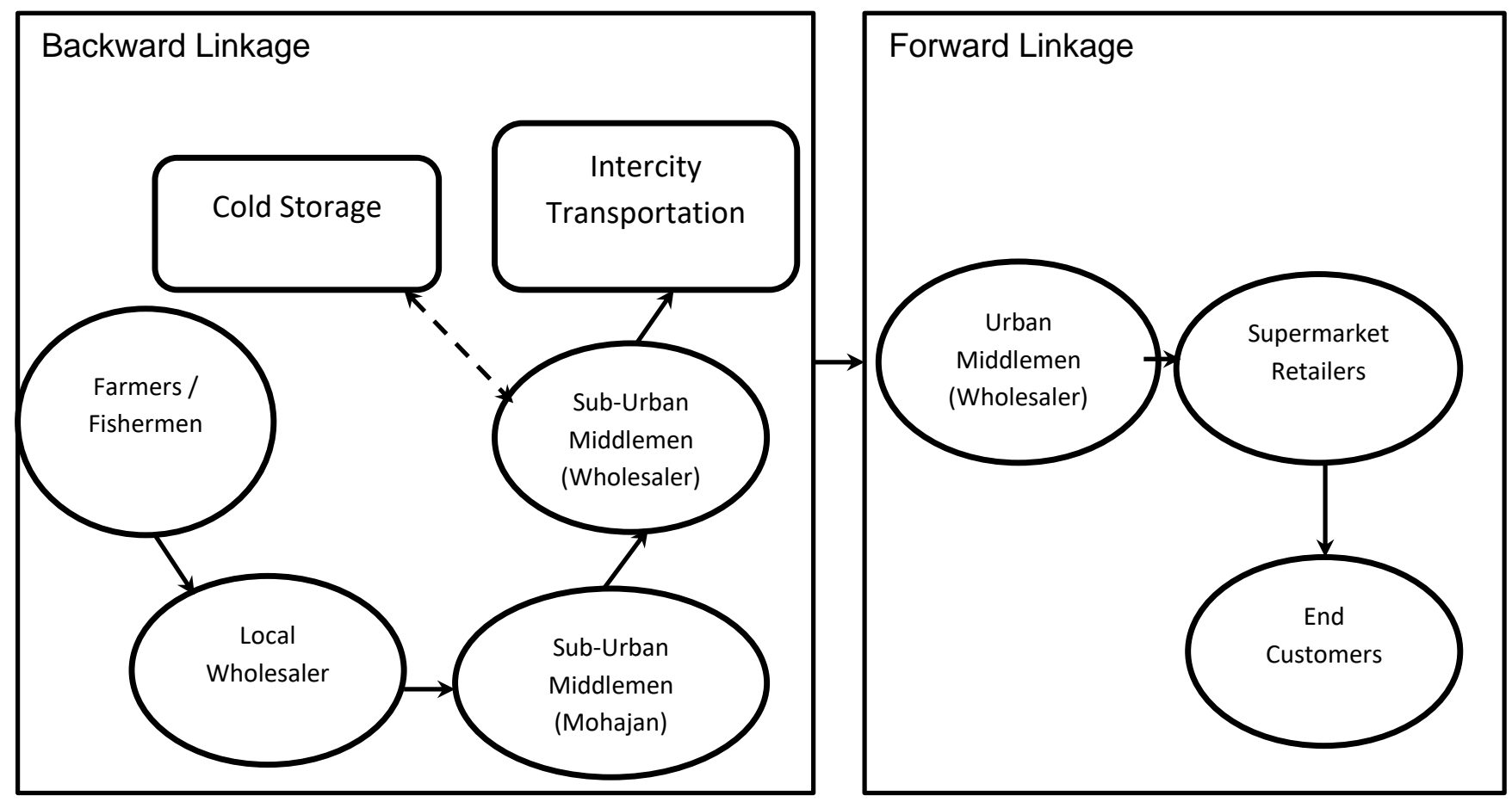

Figure 1. A common supply chain network for agro-based products and fish

\section{Discussion and Theory Development}

Without proper understanding and analysis of group dynamics, organizational misalignment, source of conflict and power, and purposeful manipulation among autonomous entities, the generic problems related to planning, control, and operation of this supply network cannot be resolved (Zaheer and Bell, 2005; Li and Choi, 2009). All the characters, purpose, objective, dynamic coherence, and type of manipulation in perishable items should be looked at, explored, and analyzed from purely organizational relationships and operational management (Zaheer and Bell, 2005; Peng et al., 2010). The important constructs which should be analyzed are attitudes and motives, opportunistic behavior, structural conflicts and power, collaborative performance, operational interdependencies, and transactional cost (Matos and Hall, 2007; Pagell et al., 2010; Choi and Linton, 2011; Mena et al., 2013).

Shedding light on stakeholder theory (Phillips, 2003; Freeman et al., 2004; de Brito et al., 2008; Park-Poaps and Rees, 2010), it is explicitly reasonable to consider all the members playing some kind of roles in procurement, inventory control, and planning, packaging, logistics management, and distribution as the stakeholder. In that sense, all the middlemen who are considered forming redundant nodes and networks in the structure of the supply chain, but playing a vital role, are stakeholders of the existing supply chain of agro items and fishes. Now, look at the agency theory. According to this theory, the principals hire the agents to fulfill their goals and accomplish the desired tasks (Eisenhardt, 1989; Hill and Jones, 1992). Streamlining the overall process, facility, 
functionality, and the topology of the supply chain of perishable items procured from rural and remote places, the farmers or fishermen and the retailers can be proposed as the principals and the nonessential middlemen can be regarded as the agents. In the light of present network and structural dynamics, those middlemen should be considered as the agents, since they play a vital role to connect the principals, and apparently, they are recruited by the principals to maintain the flow of the supply chain and establish a connection. Arguably, they are stakeholders. Now for stable structure, are they necessary to maintain the connectedness between the principals? If not, they should not be considered as the agent and, thus should be removed from the identity of stakeholders.

It is imperative to analyze the dilemma of agency in the supply network of perishable items. Integrating the true essence of stakeholder theory and agency theory, responsibility, accountability, and authority of different stakeholders differ significantly based on the implied interests of the agents in launching the supply from the source to the end customers. The distribution of profit of any stable supply chain may vary depending on the relationships between the principals and agents and their functionality (de Brito et al., 2008). However, after analyzing the role of agency in the supply chain of perishable items, such as vegetables, fruits, flowers, and fishes, it is realized that agents are attempted to capitalize more benefits depriving the principals based on their capacity, power, and manipulated role (Singh, 2011; Mena et al., 2013) which is potentially contradictory in managing a resilient supply chain (Park-Poaps and Rees, 2010).

In the supply chain of complex organizational orientation where several organizations are working, it is prevalent that mutual cooperation is essential to stimulate core competencies of each organization to support the entire chain (Hong and Jeong, 2006). In this regard, the study of Li and Wang (2007) postulated that without inter-organizational integration of core competencies, interdependent organizational dynamics cannot ensure synergistic performance. Separated and detached organizations, staying in the same loop of the supply chain while searching for only selfbenefits from the output of the supply chain performance depriving others, ultimately generate an unstable network (Cao et al., 2008). An extensive study conducted by Arshinder and Deshmukh (2009) to investigate inter-organizational conflicts and their impact on supply chain performance revealed that networked organizational members commonly manage several resources like inventory, logistics, money, and information. Despite this interdependency, when organizations having disparate motives in the supply chain of perishable items try to hide information important for resource management, lack of comfortableness arises in the close network (Singh, 2011). This ill-competition among the members of a supply chain leads to increase cost, long lead time, distortion of demand, i.e. bullwhip effect, quality deterioration, and uncertainty (Stephenson, 2005; Balcik et al., 2010; Dwivedi et al., 2018). This phenomenon is fundamentally against the overarching and central concept of forming any supply chain with a multi-organizational group (Grittell and Weiss, 2004). In this regard, several authors (Jharkharia and Shankar, 2005; Singh, 2011) are increasingly interested and recommend intensifying the use of interpretive structural modeling (ISM) where organizational disparities will be investigated, their goals will be aligned, 
common coordination index will be settled, and mutual benefits will be reallocated based on their performance not based on power. However, ISM is not applicable for this kind of manipulated supply chain where organizational conflict is introduced purposefully, and disparate goal of organizations is not the reason for organizational differences; rather it is artificially developed to deprive other members (Stock, 1997; Surana et al., 2005; Mena et al., 2013).

Intra-organizational homogeneity (among middlemen or agents) and inter-organizational heterogeneity ultimately hamper cohesiveness among the stakeholders of the supply chain (Stephenson, 2005; Dubey and Gunasekaran, 2015b; Dwivedi et al., 2018; Gunasekaran et al., 2018). Conflict of interest among the members of different organizations is due to the absence of inter-organizational relations (Emerson, 1962; de Charms, 1968; Cordova and Lepper, 1996; Stock, 1997). These interdependent organizational complexities can be analyzed in the light of organizational theory dealing with complex behavior like the cognitive dissonance theory of Leon Festinger (1962). This is a behavioral theory that posits the psychological unstable status of human beings while facing a contradiction between their motives and actions. If organizational members perceive contradiction or conflicts between their attitude and behavior, i.e., if behavior and attitude are not aligned, they feel uncomfortable. This status is called an unstable mental situation. At that point, the common trend is that they attempt to remove conflicting attitudes or pursue behavior or attitudes to change to make it consistent with motives and final actions. When it is possible, this mental status is called a stable situation. It is human psychology. In the light of multiorganizational conflicts, while dealing with members of other organizations, the principals (farmers/fishermen and supermarket retailers) are forced to behave in a way that they do not perceive in their mind. In that case, they feel a serious confrontation between their attitudes toward that action and final behavior which causes uncomforting and deteriorating performance (Rusbult and Van Lange, 2003; Reich, 2006; Chen and Risen, 2010). This is the case of both principals, particularly for the farmers and fishermen. An uncomfortable and unstable mental condition also arises when agents (middlemen) design their route of behavior willingly but have conflicts in their motives since they show one type of motives externally to other members but conceive different ill motives that are concealed, not exposed. This is applicable to the agents representing the middlemen.

Now contrast this organizational theory with the distinctive characteristic of the supply chain of vegetables, fruits, flowers, and fishes manifesting functionality including logistics management, planning, and control of inventory, organizational interaction, information sharing, topology, technology, and financial exchange. In the aforementioned dissonance of the principals, remote principals, primarily located in rural areas (farmers/fishermen) find their attitude and behavior not aligned. They are forced to sell their collected fish or cultivated agricultural products to the nearest suburban markets controlled by Mohajan/Investor/Store owner/ (middlemen) at the price, settled by the commission agents and other middlemen.

Looking at the second dissonance of the middlemen, all the local middlemen and middlemen in big cities who basically establish a fragile bridge between farmers/fishermen (principal) and 
supermarket retailers (principal) are purposefully endeavored to detach these two essential principles. They control demand and supply to artificially generate the market status of surplus supply (for the suppliers at source) and surplus demand (for the end seller, i.e., retailers). Therefore, their actions (behavior) to manipulate the operation of the supply chain are willful. They also hide information about the quality standards, obstruct the flow of information, manage logistics poorly whenever needed, and hike prices considering future demand. However, their exposed attitude is not aligned with this behavior. They are attempting to show that this market manipulation is due to the detrimental performances of the principals.

This forceful sale of the farmers/fishermen and scopes of the middlemen to play in the supply chain are due to the following genuinely and artificially created reasons:

1. The farmers and fishermen do not have communication with the supermarket retailers in big cities

2. Although they are the suppliers at the source and should have control over inventory planning at the origin, they do not have a hold on planning and control on inventory, pricing, and distribution.

3. They do not have information about specific present or future demand

4. They do not have knowledge about the quality standard

5. The sole purchasers of their products available in the nearest semi-urban markets are the Mohajan/Investor/Store and the commission agent.

6. Scope to exercise power is substantially higher for these middlemen in comparison to the farmers and fishermen

7. Farmers and fishermen are very poor, scattered, illiterate, and not conscious about their rights and power

8. Local market close to the rural or remote farmers and fishermen are underdeveloped and completely controlled by these local middlemen

9. Transportation facilities are very limited, and farmers and fishermen have no control over inter-district logistics

10. Local preservation resources such as cold storages, packaging materials are inadequate in amount and controlled by the middlemen.

11. There is no active market control mechanism introduced and exercised by the government to regulate this manipulation of demand, supply, and excess stockpiling.

12. Technological innovation in organizational communication and information sharing, logistics management, demand forecasting, procurement, and distribution is extremely inadequate, poor, and not secured.

13. Profit-sharing is extremely power-dependent and manipulated. There are no regulations to oversee social equity.

Analyzing literature on the supply chain of perishable food items, such as flowers, agricultural foods, and fishes where supply networks of these items for different countries were analyzed, for instances, Europe (de Brito et al., 2008), India (Dubey et al., 2018a), Honduras (Bloom, 2015), 
Norway (Dreyer et al., 2016), Taiwan (Chang and Meyerhoefer, 2020), and Thailand (Schipmann and Qaim, 2011), it is quite evident that the aforementioned issues of inter-organizational conflicts are very common and profoundly observed.

Contrasting theory of conflict in the organizational context (Emerson, 1962; de Charms , 1968; Van de Vliert and Kabanoff, 1990; Ertmer and Newby, 1993; Twomey, 1995; Wall and Callister, 1995; Rahim, 2002; Bar-Tal, 2007; Risen and Chen, 2010;) with special attention on the type, pattern, and outcome of the manipulations in the structural dynamics and associated disruption risks leading to ripple effect, these conflicts present in the supply chain shown in Figure 1 can be denoted by dysfunctional conflict. Under this conflict in the manifest stage, participating members impose as well as experience confrontations that are subversive to the growth and functionality of the organizational integration and entire topology of the network. The situation and motive of this conflict is predetermined, purposeful, intended, and designed to secure benefits only for its own organization or entity. Interestingly, this benefit is generated in their entire network due to the functionality and process executed by all the members and due to their synergistic performance. Also, another interconnected motive is to deprive the other parties in the network purposefully, although all of them are members of the same network. The noteworthy issue is, due to the subversive exercise of power by the middlemen, the performance of the principals will be hampered in the future, knowing that agents continue this behavior. Pragmatically, this is completely market manipulation; the crisis is generated artificially and must be regarded as unethical.

On the other hand, analyzing the behavior and attitude of the farmers and fishermen, their pattern of conflicts introduced in this inter-organizational dynamic is functional (Van de Vliert and Kabanoff, 1990; Wall and Callister, 1995; Rahim, 2002). That means the attitude and motive they perceive and the behavior they like to incorporate in this network are favorable for the effective design of this supply network. Similarly, supermarket retailers have a passion to keep priceless to increase sales and earn more revenue. These two principals (farmers and fishermen and the retailers) eagerly try to secure their equitable profit from this entire operation which is quite justified and reasonable; nevertheless, they also aim to maintain a balance between supply and demand fixing price reasonably. To design a cost-effective, efficient, and resilient supply chain with balanced structural dynamics is fruitful and thus, should be termed as beneficial for the organizational interaction (functional).

So, this scenario, considering typical group dynamics and inter-organizational interactions in any supply chain, is extremely unusual and uncommon since two opposite types of conflict dimensions exist in the same connected (apparently, actually open loop) network, both functional and dysfunctional. The complex question and concern are how to resolve these two controversial and contradictory situations. In the same supply network which is presumably connected, in the interorganizational conflicts, the principals are pursuing functional conflicts to reduce lead time, maintain quality, curtail lengthy chain, and reduce the price for the end customers whereas the agents are purposefully injecting dysfunctional conflicts to hamper the inter-organizational 
relationships. Therefore this conflict scenario is heterogeneous and complex, a confrontation between dysfunctional and functional conflicts. It is a practical dilemma.

Shedding light on the theoretical ground of common conflict management styles in organizational life (Van de Vliert and Kabanoff, 1990; Ertmer and Newby, 1993; Wall and Callister, 1995; Twomey, 1995; Black, 1998; Rahim, 2002; Belaya and Hanf, 2009; Risen and Chen, 2010), it is observed that the behavioral procedures under this scenario could be competing, avoiding, accommodating, compromising, and collaborating. However, collaborating can be excluded as the conflict introduced in this network is purposefully, so collaborating attitude is not expected from the agents practicing unethical behavior.

From interviews, observations, and analysis of the role, responsibility, functionality, organizational interaction, authority, and performance, it is explicit that both the principals should be considered as the essential members of this value chain. Without their actions and performance, this chain cannot be completed and cannot produce any fruitful and purposeful results. It is argued by this study that these two members, as the fundamental and primary stakeholders of the value chain, deserve to claim justified profit generated from their functionality. So, supply chain topology should consider their right as justified, ensure their presence as the inevitable nodal points, and promote their connectedness as the essential members. Considering the status in the supply chain, since the principals have the right to get a share of revenue on the basis of equity, for handling organizational conflict, both the principals must try to win to position, establish, and claim their rights following competing for management style.

In competing for management style, the deserving party (in this case both the principals) can legitimately strive to claim justified profit from the revenue generated in the operation of this supply chain and can put their efforts to win over the agents resolving the created conflicts, since they are in the right path (See literature on conflict, de Emerson, 1962; de Charms, 1968; Ertmer and Newby, 1993; Twomey, 1995; Black, 1998; Belaya and Hanf, 2009; Risen and Chen, 2010). From our previous analysis, it is explicitly proved with enough evidence that agents (middlemen) are intervening in this chain by exercising unethical power and putting their efforts to deprive the farmers and fishermen and end customers. They are the source of this unwanted conflict where they are capturing more profits than they deserve from this supply chain with respect to their involvement in generating revenue from the operation. Therefore, in the light of organizational conflict management style (Van de Vliert and Kabanoff, 1990; Ertmer and Newby, 1993; Twomey, 1995; Wall and Callister, 1995; Rahim, 2002; Risen and Chen, 2010), they cannot claim to win over this conflict and thus, their conflict management style must not be competing; nevertheless, they follow this style to win over this conflict at any cost.

Focusing on the accommodating style in conflict management style, one party wishes to sacrifice his/her interest to let the other party gain the benefits (Van de Vliert and Kabanoff, 1990; Twomey, 1995; Wall and Callister, 1995; Dubey et al., 2016). In this case, although unwillingly, while dealing with the agents, both the principals are accustomed to this conflict resolution style. During 
inter-organizational interactions, agents should follow this style since they are not the primary source of generating revenue in the operation of this supply china. However, their resolving styles are quite the opposite. Principals are openly following the accommodating style, although unwillingly. And the agents are following competing styles secretly. From the interviews, arguably, it can authentically claim that the supermarket retailers are trying to avoid this confronting situation since they are dependent on the middlemen. So, they are, to some extent, for a time being, following avoiding style to manage the conflict. In avoiding style, parties may avoid the situation for a time being, since it cannot be managed by them in the present scenario (Twomey, 1995; Wall and Callister, 1995). However, who is paying the cost? The suppliers (farmers and fishermen) and the end customers (paying higher prices) are incurring the loss. Therefore, from the retailers' perspective, the following avoiding style is not acceptable as it is the opportunistic view.

Although, may not be the most appropriate way; however for a realistic solution, analyzing conflict management style in inter-organizational confrontation, "compromising" can be applied. From the interviews of the principals, it is obvious that they are ready to negotiate with the agents and can sacrifice to some extent so that the agents will also sacrifice the same amount to settle a midpoint deal which is called compromising in inter-organizational conflicts (Van de Vliert and Kabanoff, 1990; Twomey, 1995). Realistically, due to their scope to exercise seamless power without any obstructive force, agents will not go for any compromise to resolve this conflict.

Therefore, from this qualitative study of extensive interviews, it is clearly recognized that this organizational conflict raised due to the exercise of unethical power by the agents is not in a state to be resolved. On the other hand, the producers (farmers and fishermen) are helplessly and unwillingly accommodating with this complex conflict in the presence of redundant networks in their supply chain where they legitimately can claim the ownership. It is creating cognitive dissonance in them (see the theory, Collins and Hoyt, 1972; Cooper and Fazio, 1984; Gagne et al., 1993; Cordova and Lepper, 1996; Black, 1998; Belaya and Hanf, 2009; Chen and Risen, 2010) which is a fundamental source of fragility in the structural dynamics and ripple effect of the supply chain of vegetables, fruits, flowers, and fishes.

From a realistic view supported by an organizational conflict management style, grounded theory can be proposed to manage and develop a resilient supply chain for vegetables, fruits, flowers, and fishes. The prerequisite assumptions for this grounded theory are:

1. Government intervention is imperative, and it should be active to oversee, monitor, and coordinate the network inevitably required to procure these products from the farmers and fishermen and distribute them to the warehouse of the supermarket retailers.

2. Mobile information technology (MIC) should be incorporated between the two principals.

3. Now organizations are facing serious challenges in managing group dynamics and formal activities while maintaining social isolation. During the current pandemic situation, mobile technology has substantial importance due to social isolation. 
4. In the light of MIC, both the principals will communicate continuously through a smartphone using a cross-platform voice over IP (VoIP) and instant messaging (IM) software, and this connection will be seamless.

5. Under MIC, mobile operating companies will participate in this network externally to authenticate communication and contract between the two principals.

6. Under MIC, authorized mobile money transfer companies should be included in this network externally to authenticate and facilitate money transfer from the retailers to the end rural farmers and fishermen instantly.

7. A close-loop through interconnectedness will be established among the members of this supply chain for better cooperation and interoperability.

8. With the assistance of the government, all nonessential middlemen (agents) should be removed from this network to i) support the farmers and fishermen to hold their deserving revenue, ii) help the end customers to get the products at the justified price, iii) maintain the quality standard, iv) actively monitor the market and legitimately stop any effort to manipulate the market, v) shorten lead time, vi) support and promote the supermarket retailers, vi) control cold storage, logistics management, packaging, demand and supply, and inventory management and, vii) oversee the distribution of profit on the basis of equity.

Based on the aforementioned identification, in the light of multi-organizational interactions and group dynamics where there is no unethical scope to exercise illegitimate power and play opportunistically, this study is proposing a grounded theory to manage the supply chain of vegetables, fruits, flowers, and fishes in a different fashion. Under the present condition, effective design of the supply chain should also consider the inevitable requirement of social isolation. For this kind of supply chain where one party is completely scattered and unorganized, illiterate, has very limited knowledge to share information seamlessly and get access to requirements to other parties, and has no scope to preserve own rights from market competition, the private-public partnership is imperative. The two principals should maintain a direct network between them with another active nodal point formed by the government to facilitate this supply chain. Under MIC, mobile operators and mobile money transfer service providers will also participate as the external resource supplier. This supply chain can be defined here as the private-public partnership chain (PPPC). The following figure (Figure 2) is the schematic view of this network. The dotted lines in Figure 2 are the proposed relations of government and mobile operators with other members in the supply chain. The government will monitor all the three members, farmers or fishermen, supermarket retailers, and commission agents (shown in Figure 2 by dotted lines). A relation will be established between the farmers or fishermen and supermarket retailers through the mobile operators to conduct an auction (shown in Figure 2 by dotted lines). For efficient procurement after the auction, in favor of the retailers, a relation is essential between the farmers or fishermen and commission agents (shown in Figure 2 by dotted lines). 


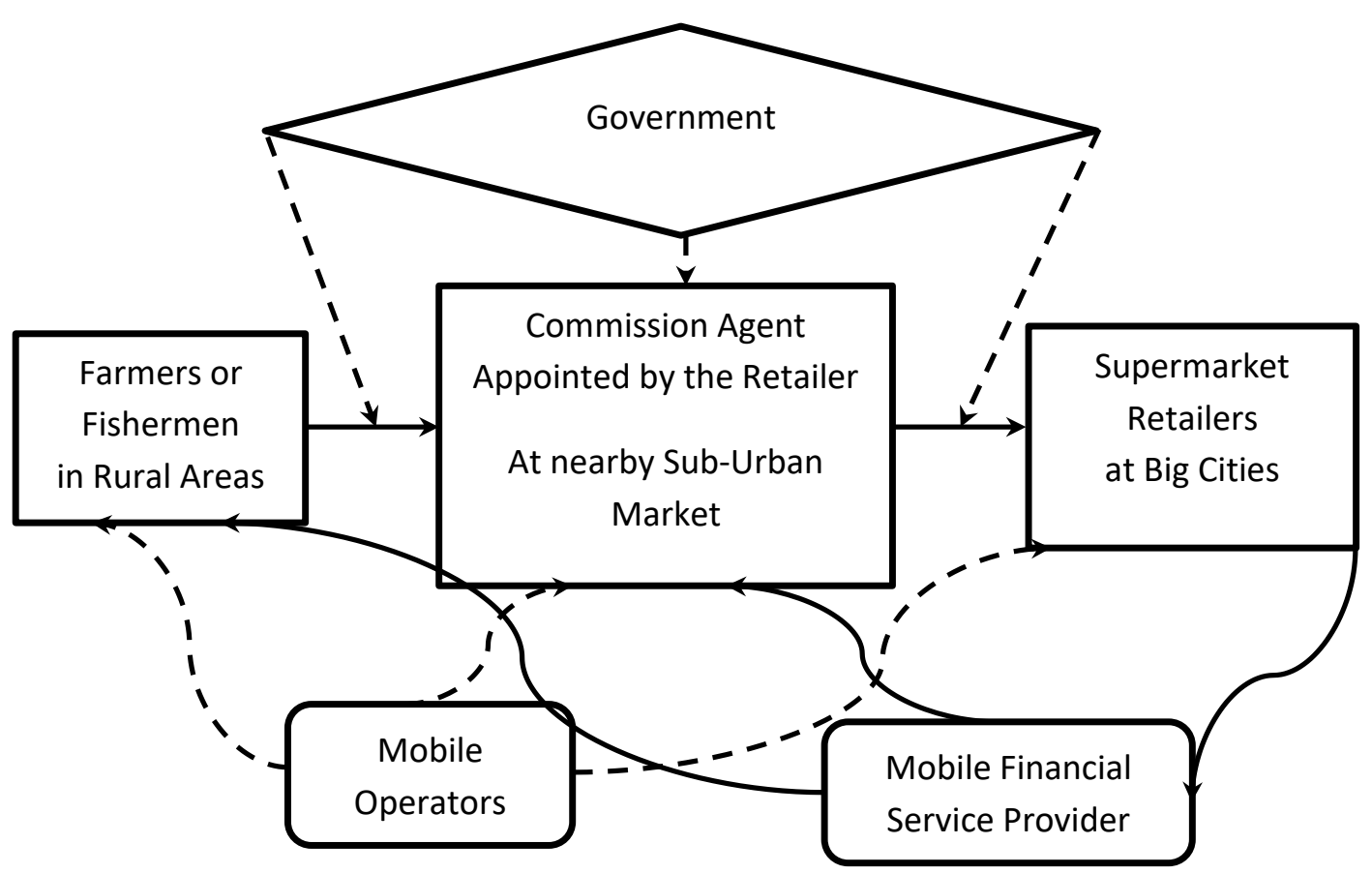

Figure 2. A model of private-public partnership chain (PPPC)

\section{Theoretical and Managerial Implications}

Theoretical and managerial implication of this research is enormous. It has a substantial contribution to the existing knowledge of playing, controlling, and managing agro-based and fish supply chains in developing countries, particularly during this covid-19 pandemic situation where social isolation and lockdown is the only solution, so far. Many researchers (Balcik et al., 2010; Gopal and Thakkar, 2016; Dubey et al., 2018a; Dwivedi et al., 2018; Campos et al., 2019; Shareef et al., 2019; Zhang et al., 2019) have investigated these supply chains from the perspectives of efficiency, information sharing, technology innovation, and logistics management. Several studies also explored and addressed the presence of middlemen who are responsible to hike prices (Surana et al., 2005; Singh, 2011; Fawcett et al., 2012; Mena et al., 2013). They also manifested the scope of exercising uneven power (Black, 1998; Rusbult and Van Lange, 2003; Reich, 2006; Belaya and Hanf, 2009) and acknowledged the presence of conflicts that may hamper the development of a resilient supply chain (Balcik et al., 2010; Gopal and Thakkar, 2016; Dubey et al., 2018a; Dwivedi et al., 2018; Shareef et al., 2019). Researchers also investigated fragile structural dynamics due to disruption risks and ripple effects in this rural-based supply chain (Dreyer et al., 2016; Dolgui et al., 2018). However, hardly any scholarly studies have thoroughly investigated the supply chain of vegetables, fruits, flowers, and fishes from the light of inter-organizational conflict management style and how the agents, i.e., middlemen can get the scope to exercise power, manipulate the supply of China structure, create excessive nodal points, lengthen network, and hike the price. 
Researchers did not accentuate on the group dynamics of these middlemen from the true multiorganizational interaction perspective. Therefore, this study has unfolded a new area of research to identify and analyze the performance of the supply chain in light of organizational conflicts.

So far researchers (Emerson, 1962; de Charms, 1968; Van de Vliert and Kabanoff, 1990; Ertmer and Newby, 1993; Twomey, 1995; Rahim, 2002; Bar-Tal, 2007; Risen and Chen, 2010) have figured out conflict in the supply chain from an operational management perspective. This conflict is the byproduct of the operation. However, this research has provided a new area for the researchers that this conflict and confrontation between the principals and the agents is intentional and manipulated purposefully. It is not the by-product of the operation; rather it is injected illegally with the support of the unethical power of the local village or sub-urban middlemen. This study also has shown that this conflict is not something to be resolved because here one party is creating functional conflict and the other party is moving in the opposite direction by introducing dysfunctional conflict. The existence of functional and dysfunctional conflicts in the same supply network and how it can be detrimental to the performance of the members are exposed in this study which can be an excellent source to be investigated by academics.

Academics can find it interesting to realize the potential presence of the government and recognize their inevitable support. The proposed model PPPC based on the grounded theory of private-public partnership clearly can streamline a theoretical avenue for the researchers. The necessity of private-public partnership for the smooth operation of private business can be again felt by the academicians and they further investigate its performance through analyzing government influence.

Managers can also get an excellent idea about the topology of the supply chain when they purchase perishable items from the farmers and fishermen. Generally, managers of private organizations oppose any intervention of government in their independent movement; however, they can get a new thought and deliberate over this finding to realize how inevitable it is to include government in their procurement and distribution chain for smooth operation and stable structural dynamics. For competitiveness in the market of developing countries and emerging economies, they can beat traditional uncovered Bazars (called it Katcha Bazar) and small grocery stores, if price and quality are kept reasonable (Levitt, 1983). However, the present middlemen will not allow this competitive model unless the government intervenes in this network and removes those redundant middlemen.

Managers and practitioners can also strive and perceive the importance of the inclusion of MIC in their supply network to facilitate seamless communication with the suppliers at the source. Formal support from the mobile operating companies and mobile money transfer service providers can facilitate smooth operation. Practitioners can propose to the government to oversee this entire network through their legitimate power. Managers can also negotiate with the MIC service providers to be included externally in this supply network to form an excellent close loop with active support. 
From the aforementioned discussion, it is quite evident that the findings of this study can provide deeper knowledge and experience to academics and practitioners. Supply chain experts can learn how middlemen in any network of perishable food items raise the price, control the entire value chain, and deprive both the customers and farmers/fishermen to get appropriate price and profit. Organizational behavioral theorists get experience about a new dimension of conflict management where the principals have no control. This study has provided substantial practical knowledge to the government policymakers and market analysts about the unorthodox price hiking of perishable food items where non-essential middlemen are playing the crucial role. Therefore, the theoretical and managerial implication of this study is enormous.

\section{Conclusion}

This study is intended to investigate the supply chain of agricultural food items, for instance, vegetables, fruits, and flowers, and fishes considering inter-organizational conflicts. Here special attention should be provided to the current pandemic situation where social isolation is mandatory. Literature review (de Brito et al., 2008; Park-Poaps and Rees, 2010; Dreyer et al., 2016; Dubey et al., 2018a; Dwivedi et al., 2018) suggested that the supply chain of manufacturing items have been analyzed and optimized for many years. Many scholarly articles (Balcik et al., 2010; Gopal and Thakkar, 2016; Dubey et al., 2018a; Dwivedi et al., 2018; Shareef et al., 2019) have also explored the supply chain of perishable items particularly agro-based items and fishes and attempted to reveal their structural dynamics including topology, financial management, organizational interactions, information technology, and functionality. In this regard, special attention was given to understand the root causes of inefficiencies of these supply chains for developing countries (Schipmann and Qaim, 2011; Trienekens, 2011; Bao et al., 2012; Bosona and Gebresenbet, 2013; Somashekhar et al., 2014; Bloom, 2015; Silvestre, 2015; Emana et al., 2017; Zhang et al., 2019). These research papers have postulated many reasons including the most common, for instance, longer lead time, lack of information and its sharing, less access to information, lack of technological innovation, poor rural communication, shortage of resources and poor management of logistics, weak road communication, and inter-organizational conflicts.

However, while detecting and illustrating inter-organizational conflicts, these studies have focused on the lack of scope and opportunity for the members of supply networks and unwillingness to share information. The studies did not accentuate intentional motives to destabilize the market, manipulate supply and demand, and snatch the major share of profit by depriving the principal members of the supply chain. Despite acknowledging the presence of tremendous conflicts among the members, no studies have thoroughly investigated the conflicts from the light of organizational relations contrasting operations management. Nevertheless, without analyzing the sources of conflicts among the members from truly organizational relations and group dynamics, the root causes of these conflicts cannot be unfolded and theorized. Under this context, this study has set its twofold objectives to identify the root causes of conflicts in the existing structural dynamics shedding light on organizational interactions, power, and group behavior, and develop an optimal topology of structure based on grounded theory. This study was designed to capture the essence 
of conflicts and organizational confrontation with unethical behavior and manipulation through observation, discussion, and interviews.

This study is an attempt to study this area through exploratory investigation. In this context, investigating the field, observing the members of the existing supply chain from rural and remote places, capturing their interviews are the realistic methods to accomplish the objectives. Considering the scenario of the existing supply chain with two remote principals (farmers, fishermen in rural areas, and supermarket retailers in big cities) and many redundant middlemen who constitute the unstable, open network with apparent connectedness, a qualitative study is assumed to be the appropriate way to investigate (supported by Choi et al., 2016). Among many reasons, the most common issues are: i) Information is scattered, ii) Problem is not explicitly identified, iii) Initially, the researchers were not sure about findings, iv) Even the nodal points of this supply chain representing different members are not recognized initially, v) Behavior and group dynamics of the middlemen is unstructured and unstable, v) Attitude and behavior of the middlemen is potentially contradictory, vi) The action of the middlemen is intentionally manipulated.

Considering the above uncertainties, this study was designed to capture the essence of conflicts and organizational confrontation with unethical behavior and manipulation through observation, discussion, and interviews. In this regard, from the primary investigation, members of this supply chain were identified. Then detailed field investigations were done through extensive interviews and discussions at different locations. Several members of all the organizations directly involved in this apparently connected network were under this investigation. Opinions were also collected from the ancillary service providers such as cold storage owners, transport agencies, and packaging material suppliers. Integrating the collected information, the researchers felt the necessity to discuss with government authorities, mobile phone operators, and mobile money transfer service providers.

The findings are listed in Table 1 and a schematic view of the existing supply chain was drawn in Figure 1. Considering the nature of imposed and artificially created conflicts, inter-organizational group behavior, display and exercise of excessive power, and distribution of revenue, the researchers have focused on several organizational theories, for instance, cognitive dissonance theory, conflicts development theory, and conflict management style in complex and multidimensional organizational interactions. It was aimed to understand, analyze, and develop a grounded theory to optimize the process of the supply network.

Finally, it was concluded that although this supply chain is controlled truly by private parties, from a realistic view, in this context, the private-public partnership is essential where the government should play the overall supervisory role (supported by Lu and Yang, 2004; Li, 2007; Mena et al., 2013; Rais and Sheoran, 2015; Moazzam et al., 2018). Concerned government agencies should interact with both the principals (farmers and fishermen, and supermarket retailers) to establish a fair and robust value network for vegetables, fruits, flowers, and fishes so that rights of the poor 
and unorganized farmers and fishermen are protected as well as the demand of customers to get a fair price is ensured. Previous scholarly research studies conducted by Dwivedi et al. (2018) and Shareef et al. (2019) also justified this finding. In this connection, the application of mobile information communication (MIC) should be introduced between these two parties to maintain dynamic and seamless relations which is also supported by Shi et al. (2016). It was also recommended to remove all the redundant middlemen through the intervention of the government. Reflecting on the grounded theory of the private-public partnership chain (PPPC), a robust supply network model is proposed. While designing this model, special attention should be provided to the current pandemic situation caused by Covid-19 where social isolation is extremely important.

\subsection{Limitations and Future Research Guideline}

As an exploratory and qualitative investigation, this research has several limitations that can be overcome by future researchers following this PPPC model. It was conducted in only one country. Cultural orientation can have an impact on the qualitative study. Similar research can be conducted in several countries on the supply chain of vegetables, fruits, flowers, and fishes. For the supply chain of fishes in Bangladesh, this study has mainly focused on Hilsa fish which occupies the highest proportion of the fish market. Future researchers can extend this study to other fishes.

In this study, the private-public partnership is proposed through government interventions. In the privately operated supply chain, the involvement of the government may raise several constraints. These are not tested. Future researchers can experiment with the type, pattern, and extent of government involvement and define the periphery of private-public partnerships in the market economy. Under the grounded theory, nonessential middlemen are proposed to be removed; however, future researchers can experiment with the feasibility of this exclusion. In addition, after the exclusion, how this direct relationship may work should be tested through a quantitative study.

Acknowledge: This research is funded by Strengthening of Hilsa Research in Riverine Station Chandpur Project, Bangladesh Fisheries Research Institute, Riverine Station, Chandpur, Government of Bangladesh.

\section{Reference}

Ahmed, N., Rahman M.M., and Rahman, M.M. (2008), "A Study on Fish Marketing Systems in Gazipur”, Pakistan Journal of Biological Sciences, Vol. 8 No. 2, pp. 287-292.

Aker, J.C.( 2010), "Information from Markets Near and Far: Mobile Phones and Agricultural Markets in Niger”, American Economic Journal: Applied Economics, Vol. 2 No. 3, pp. 46-59.

Al-Hasan, A., Shahjahan, M., Hossain, M. M. and Haque, M. M. (2014), "Fish Availability and Marketing System at Three Markets in Barisal, Bangladesh”, International Journal of Innovation and Applied Studies, Vol.7 No. 2, pp. 765-773. 
Ali, I., Nagalingam, S., and Gurd, B. (2017), "Building resilience in SMEs of perishable product supply chains: enablers, barriers and risks”, Production Planning \& Control, Vol. 28 No. 15, pp. 1236-1250.

Arshinder, K.A. and Deshmukh, S.G. (2009), "A framework for evaluation of coordination by contracts: a case of two-level supply chains", Computers \& Industrial Engineering, Vol. 56 No. 4, pp. 1177-91.

Balcik, B., Beamon, B.M., Krejci, C.C., Muramatsu, K.M., and Ramirez, M. (2010), "Coordination in humanitarian relief chains: Practices, challenges and opportunities", International Journal of Production Economics, Vol. 126 No. 1, pp. 22-34.

Bao,L, Huang, Y., Ma, Z., Zhang, J. and Lv. Q. (2012), “On the Supply Chain Management Supported by E-Commerce Service Platform for Agreement based Circulation of Fruits and Vegetables", Physics Procedia, Vol. 33, pp. 1957-1963.

Bar-Tal, D. (2007), "Sociopsychological foundations of intractable conflicts", The American Behavioral Scientist, Vol. 50 No. 11, pp. 1430-1453.

Beamon, B. M., and Balcik, B. (2008), "Performance measurement in humanitarian relief chains”, International Journal of Public Sector Management, Vol. 21 No. 1, pp. 4-25.

Beamon, B. and Kotleba, S. (2006), "Inventory management support systems for emergency humanitarian relief operations in South Sudan", The International Journal of Logistics Management, Vol. 17 No. 2, pp. 187-212.

Belaya, V., and Hanf, J. H. (2009), “A multi-theoretical perspective on power in managing interorganizational relationships", International Journal of Social Economics, Vol. 36 No. 11, pp. 1040-1049.

Birkie, S.E. and Trucco, P. (2020), "Do not expect others do what you should! Supply chain complexity and mitigation of the ripple effect of disruptions", The International Journal of Logistics Management, Vol. 31 No. 1, pp. 123-144.

Black, D. (1998), “The social structure of right and wrong”. San Diego, CA: Academic Press

Bloom, J. D. (2015), "Standards for Development: Food Safety and Sustainability in Wal-Mart's Honduran Produce Supply Chains” Rural Sociology, Vol. 80 No. 2, pp. 198-227.

Bosona, T. and Gebresenbet, G. (2013), "Food traceability as an integral part of logistics management in food and agricultural supply chain", Food Control, Vol. 33 No. 1, pp., 32-48.

Campos, P. F., Trucco, P., and Huaccho Huatuco, L. (2019), "Managing structural and dynamic complexity in supply chains: insights from four case studies", Production Planning \& Control, Vol. 30 No. 8, pp. 1-13. 
Cao, N., Zhang, Z., To, K.M. and Ng, K.P. (2008), "How are supply chains coordinated? An empirical observation in textile-apparel business", Journal of Fashion Marketing \& Management, Vol. 12 No. 3, pp. 384-97.

Chang, H.-H. and Meyerhoefer, C. (2020)., "COVID-19 and the Demand for Online Food Shopping Services: Empirical Evidence from Taiwan”, NBER Working Paper No. 27427.

Chaudhuri, A., Ghadge, A., Gaudenzi, B. and Dani, S. (2020), "A conceptual framework for improving effectiveness of risk management in supply networks", The International Journal of Logistics Management, Vol. 31 No. 1, pp. 77-98.

Chen, M.K. and Risen, J.L. (2010), "How choice affects and reflects preferences: Revisiting the free-choice paradigm", Journal of Personality and Social Psychology, Vol. 99 No. 4, pp. 573594.

Choi, T.M., Cheng, T.C.E., and Zhao, X. (2016), "Multi-Methodological Research in Operations Management", Production and Operations Management, Vol. 25 No. 3, pp. 379-389.

Choi, T. Y. and Linton, T. (2011), "Don't let your supply chain control your business", Harvard Business Review, Vol. 89 No. 12, pp.112-117.

Choi, T. Y. and Wu, Z. (2009), "Triads in supply networks: Theorizing buyer-supplier-supplier relationships", Journal of Supply Chain Management, 45(1), 8-25.

Choi, T. Y., Dooley, K. J., and Rungtusanatham, M. (2001), "Supply networks and complex adaptive systems: Control versus emergence", Journal of Operations Management, Vol. 19 No. 3, pp. 351-366.

Cichosz, M., Wallenburg, C.M. and Knemeyer, A.M. (2020), "Digital transformation at logistics service providers: barriers, success factors and leading practices", The International Journal of Logistics Management, Vol. 31 No. 2, pp. 209-238.

Collins, B. E. and Hoyt, M. G. (1972), "Personal responsibility for consequences: An integration and extension of the "forced compliance" literature", Journal of Experimental Social Psychology, Vol. 8 No. 6 , pp. 558-593.

Cooper, J. and Fazio, R. H. (1984), “A new look at dissonance theory”. In L. Berkowitz (Ed.), Advances in experimental social psychology (Vol. 17, pp. 229-266). Orlando, FL: Academic Press.

Cordova, D. I. and Lepper, M. R. (1996), "Intrinsic motivation and the process of learning: Beneficial effects of contextualization, personalization, and choice", Journal of Educational Psychology, Vol. 88 No. 4 , pp. 715-730. 
Cox, A., Watson, G., Lonsdale, C., and Sanderson, J. (2004), "Managing appropriately in power regimes: Relationship and performance management in 12 supply chain cases", Supply Chain Management: An International Journal, Vol. 9 No. 5, pp. 357-371.

Cox, A., Sanderson, J., and Watson, G. (2001), "Supply chains and power regimes: Toward and analytic framework for managing extended networks of buyer and supplier relationships", Journal of Supply Chain Management, Vol. 37 No. 2, pp. 28-35.

Dadzie, K.Q., Lee, E. and Dadzie, E.W. (2000), “Assessing logistics technology adoption time with event history analysis", The International Journal of Logistics Management, Vol. 11 No. 1, pp. 47-60.

Daugherty, P.J., Droge, C. and Germain, R. (1994), "Benchmarking logistics in manufacturing firms", The International Journal of Logistics Management, Vol. 5 No. 1, pp. 9-18.

de Brito, M.P., Carbone, V., and Blanquart, C.M. (2008), “Towards a sustainable fashion retail supply chain in Europe: organisation and performance", International Journal of Production Economics, Vol. 114 No. 2, pp. 534-553.

de Charms, R. (1968), “Personal causation”. New York: Academic Press.

Defee, C.C., Williams, B., Randall, W.S. and Thomas, R. (2010), “An inventory of theory in logistics and SCM research”, International Journal of Logistics Management, Vol. 21 No. 3, pp. 404-489.

Dolgui, A., Ivanov, D., and Sokolov, B. (2018), "Ripple effect in the supply chain: An analysis and recent literature", International Journal of Production Research, Vol. 56 No. 1-2, pp. 414430.

Dreyer, H. C.,Strandhagen, J. O., Hvolby, H-H., Romsdal, A., and Alfnes, E. (2016), "Supply chain strategies for speciality foods: a Norwegian case study", Production Planning \& Control, Vol. 27 No. 11, pp. 878-893.

Dubey, R., Gunasekaran, A., Bryde, D. J., Dwivedi, Y. K. and Papadopoulos, T. (2020), "Blockchain technology for enhancing swift-trust, collaboration and resilience within a humanitarian supply chain setting”, International Journal of Production Research, Vol. 58 No 11, pp. 3381-3398.

Dubey, R., Altay, N., Gunasekaran, A., Blome, C., Papadopoulos, T., and Childe, S. J. (2018a), "Supply Chain Agility, Adaptability and Alignment: Empirical Evidence From the Indian Auto Components Industry", International Journal of Operations \& Production Management (accepted), Vol. 38 No. 1, pp. 129-148. 
Dubey, R., Gunasekaran, A., Childe, S. J., and Papadopoulos, T. (2018b), "Skills needed in supply chain-human agency and social capital analysis in third party logistics", Management Decision, Vol. 56 No. 1, pp.143-159.

Dubey, R., Gunasekaran, A., Papadopoulos, T., Childe, S., Shibin, K., and Wamba, S. (2017), "Sustainable supply chain management: framework and further research directions", Journal of Cleaner Production, Vol. 142 No. Part 2, pp. 1119-1130.

Dubey, R., Gunasekaran, A., Altay, N., Childe, S. J., and Papadopoulos, T. (2016), "Understanding employee turnover in humanitarian organizations", Industrial and Commercial Training, Vol. 48 No. 4, pp. 208-214.

Dubey, R., Gunasekaran, A., and Ali, S.S. (2015a), "Exploring the relationship between leadership, operational practices, institutional pressures and environmental performance: A framework for green supply chain", International Journal of Production Economics, Vol. 160 No.February, pp.120-132.

Dubey, R., and Gunasekaran, A. (2015b), "Shortage of sustainable supply chain talent: an industrial training framework", Industrial and Commercial Training, Vol. 47 No. 2, pp. 86-94.

Dubey, R. and Gunasekaran, A. (2015c), "Education and training for successful career in big data and business analytics", Industrial and Commercial Training, Vol. 47 No. 4, pp.174-181.

Dwivedi, Y. K., Shareef, M. A.,Mukerji, B., Rana, N. P. and Kapoor, K. K. (2018), "Involvement In Emergency Supply Chain For Disaster Management: A Cognitive Dissonance Perspective", International Journal of Production Research, Vol. 56 No. 21, pp. 6758-6773.

Eisenhardt, K. M. and Galunic, D. C. (2000), "Coevolving: At last, a way to make synergies work”, Harvard Business Review, Vol. 78 No. 1, pp. 91-102.

Eisenhardt, K. M. (1989), "Agency theory: An assessment and review”, Academy of Management Review, Vol. 14 No. 1, pp. 57-74.

Emana, B., Afari-Sefa, V., Nenguwo, N., Ayana, A., Kebede, D., and Mohammed, H. (2017), "Characterization of pre- and postharvest losses of tomato supply chain in Ethiopia", Agriculture \& Food Security, Vol. 6 No. 3, pp. 1-11.

Emerson, R. (1962), "Power-Dependence Relations", American Sociological Review, Vol. 27 No. 1, pp. 31-41.

Ertmer, P. A. and Newby, T. J. (1993), "Behaviorism, cognitivism, constructivism: Comparing critical features from an instructional design perspective", Performance Improvement Quarterly, Vol. 6 No. 4, pp. 59-71. 
Fahimnia, B., Sarkis, J., and Davarzani, H. (2015), "Green Supply Chain Management: A Review and Bibliometric Analysis." International Journal of Production Economics, Vol. 162 No. April, pp. 101-114.

Fawcett, S., McCarter, M., Fawcett, A., Webb, G. and Magnan, G. (2015), "Why supply chain collaboration fails: the socio-structural view of resistance to relational strategies", Supply Chain Management, Vol. 20 No. 6, pp. 648-663.

Fawcett, S.E., Fawcett, A.M., Watson, B.J., and Magnan, G.M. (2012), "Peeking Inside the Black box: Toward an Understanding of Supply Chain Collaboration Dynamics." Journal of Supply Chain Management, Vol. 48 No. 1, pp. 44-72.

Festinger, L. (1962), "Cognitive dissonance", Scientific American, Vol. 207 No. 4, pp. 93-107.

Fosso Wamba, S., Edwards, A., and Akter, S. (2019), "Social media adoption and use for improved emergency services operations: the case of the NSW SES", Annals of Operations Research, Vol. 283 No. 1-2, pp. 225-245.

Fosso Wamba, S., Dubey, R., Gunasekaran, A., and Akter, S. (2020), “The performance effects of big data analytics and supply chain ambidexterity: The moderating effect of environmental dynamism", International Journal of Production Economics, Vol. 222 No. April, 107498.

Freeman, R.E., Wicks, A.C. and Parmar, B. (2004), "Stakeholder theory and the corporate objective revisited", Organization Science, Vol. 15 No. 3, pp. 364-369.

Gagne, E.D., Yekovich, C. W., and Yekovich, F.R. (1993), The Cognitive Psychology of School Learning.

Grawe, S.J. (2009), “Logistics innovation: a literature-based conceptual framework”, International Journal of Logistics Management, Vol. 20 No. 3, pp. 360-377.

Gunasekaran, A., Dubey, R., Fosso Wamba, S., Papadopoulos, T., Hazen, B. T., \& Ngai, E. W. (2018). Bridging humanitarian operations management and organisational theory, International Journal of Production Research, Vol. 56 No. 21, pp. 6735-6740.

Jharkharia, S. and Shankar, R. (2005), "IT-enablement of supply chains: understanding the barriers", The Journal of Enterprise Information Management, Vol. 18 No. 1, pp. 285-309.

Gopal, P. R. C., and J. Thakkar. 2016. "Analysing Critical Success Factors to Implement Sustainable Supply Chain Practices in Indian Automobile Industry: A Case Study." Production Planning and Control, Vol. 27 No. 12, pp. 1005-1018.

Grittell, J.H. and Weiss, L. (2004), "Coordination networks within and across organizations: a multi-level framework”, Journal of Management Studies, Vol. 41 No. 1, pp. 127-53. 
Gupta, W., He, B., and Sethi, S.P. (2015) "Contingent sourcing under supply disruption and competition”, International Journal of Production Research, Vol. 53 No. 10, pp. 3006-3027.

Havenga, J. and Simpson, Z. (2014), "Reducing national freight logistics costs risk in a high-oilprice environment: a South African case study", The International Journal of Logistics Management, Vol. 25 No. 1, pp. 35-53.

Hill, C. W. L. and Jones, T. M. (1992), "Stakeholder-agency theory", Journal of Management Studies, Vol. 29 No. 2 , pp. 131-154.

Hobbs, J. E. (2020), "Food supply chains during the COVID-19 pandemic. Canadian", Journal of Agricultural Economics, Vol. 68 No. Special Issue, pp. 171-176.

Hong, J., Zhou, Z., Li, X. and Lau, K.H. (2020), "Supply chain quality management and firm performance in China's food industry - the moderating role of social co-regulation", The International Journal of Logistics Management, Vol. 31 No. 1, pp. 99-122.

Hong, P. and Jeong, J. (2006), "Supply chain management practices of SMEs: from a business growth perspective", Journal of Enterprise Information Management, Vol. 19 No. 3, pp. 292302.

Hughes, L., Dwivedi, Y. K., Misra, S. K., Rana, N. P., Raghavan, V. and Akella, V. (2019), "Blockchain research, practice and policy: Applications, benefits, limitations, emerging research themes and research agenda", International Journal of Information Management, Vol. 49, pp. 114-129.

Jabbour, C. J.C., Mauricio, A. L., and Jabbour, A. B. L. D. S. (2017), “Critical success factors and green supply chain management proactivity: shedding light on the human aspects of this relationship based on cases from the Brazilian industry", Production Planning \& Control, Vol.28 No. 6-8, pp. 671-683.

Jensen, R. (2007), "The Digital Provide: Information (Technology), Market Performance, and Welfare in the South Indian Fisheries Sector", Quarterly Journal of Economics. Vol. CXXII, Issue 3, pp. 879-924.

Kellen, V. and Stefanczyk, K. (2002), "Complexity, fragmentation, uncertainty, and emergence in customer relationship management", Management, Vol. 4 No. 4, pp. 39-50.

Kiil, K. Dreyer, H. C. Hvolby, H-H., and Chabada, L. (2018), "Sustainable food supply chains: the impact of automatic replenishment in grocery stores", Production Planning \& Control, Vol. 29 No. 2, pp. 106-116.

Levitt, T. (1983), "Globalization of Markets," Harvard Business Review, Vol. 61 No. May-June, pp. $92-102$. 
Lewis, B. M., Erera, A. L. Nowak, M. A., and White, III. C. C. (2013), "Managing Inventory in Global Supply Chains Facing Port-of-Entry Disruption Risks.” Transportation Science, Vol. 47 No. 2, pp. 162-180.

Li, M., and Choi, T. Y. (2009), "Triads in services outsourcing: Bridge, bridge decay and bridge transfer”, Journal of Supply Chain Management, Vol. 45 No. 3, pp. 27-39.

Li, G., Sun, L., Gu, Y., and Dong, Y. (2007), « Self-organisation evolution of supply networks”, International Journal of Manufacturing Technology and Management, Vol. 10 No. 2/3, pp. $142-160$.

Li, X. and Wang, Q. (2007), "Coordination mechanisms of supply chain systems”, European Journal of Operational Research, Vol. 179, pp. 1-16.

Lu, Y.R. and Yang, Y.S. (2004), "Study on Distribution Patterns of E-Business Based Agricultural Products Logistics, Shaping Business Strategy in a Networked world", Proceeding of ICEB, P.169-174.

Maitlis, S. and Christianson, M. (2014), "Sensemaking in organizations: Taking stock and moving forward", The Academy of Management Annals, Vol. 8 No. 1, pp. 57-125.

Mangla, S. K., Luthra, S., Rich, N., Kumar, D., Rana, N. P. and Dwivedi, Y. K. (2018), "Enablers to implement sustainable initiatives in agri-food supply chains", International Journal of Production Economics, Vol. 203, pp. 379-393.

Matani, A.G. (2007) "Information technology improving retail marketing in agriculture. International Marketing Conference on Marketing \& Society”, IIMK. Retrieved from http://dspace.iimk.ac.in/bitstream/2259/372/1/185-186.pdf.

Matos, S. and Hall, J. (2007), "Integrating sustainable development in the supply chain: The case of life cycle assessment in oil and gas and agricultural biotechnology". Journal of Operations Management, Vol. 25 No. 6, pp. 1083-1102.

Mena, C., Humphries, A., and Choi, T. Y. (2013), « Toward a theory of multi-tier supply chain management”, Journal of Supply Chain Management, Vol. 49 No. 2, pp. 58-77.

Meso, P., Musa, P., and Mbarika, V. (2005), "Towards a model of consumer use of mobile information and communication technology in LDCs: the case of sub-Saharan Africa, Information Systems Journal, Vol. 15 No. 2, pp. 119 - 146.

Messina, D., Barros, A.C., Soares, A.L. and Matopoulos, A. (2020), "An information management approach for supply chain disruption recovery", The International Journal of Logistics Management, Vol. 31 No. 3, pp. 489-519. 
Moazzam, M., Akhtar, P., Garnevska, E., and Marr, N. E. (2018), "Measuring agri-food supply chain performance and risk through a new analytical framework: a case study of New Zealand dairy", Production Planning \& Control, Vol. 29 No. 15, pp. 1258-1274.

Moon, M. D. (2019), “Triangulation: A Method to Increase Validity, Reliability, and Legitimation in Clinical Research", Journal of Emergency Nursing, Vol. 45 No. 1, pp. 103-105.

Mussell, A., Bilyea, T., and Hedley, D. (2020), “Agri-food supply chains and Covid-19: Balancing resilience and vulnerability", Agri-Food Economic Systems, Guelph, Ontario, www.agrifoodecon.ca.

Cranfield, J. (2020), "Framing consumer food demand responses in a viral pandemic", Canadian Journal of Agricultural Economics, Vol. 68 No. Special issue, pp.151-156.

Pagell, M., Wu, Z., and Wasserman, M. (2010), “Thinking differently about purchasing portfolios: An assessment of sustainable sourcing”, Journal of Supply Chain Management, Vol. 46 No. 1, pp. 57-73.

Park-Poaps, H. and Rees, K. (2010), "Stakeholder forces of socially responsible supply chain management orientation”, Journal of Business Ethics, Vol. 92 No. 2, pp. 305-322.

Pathak, S. D., Day, J. M., Nair, A., Sawaya, W. J., and Kristal, M. M. (2007), “Complexity and adaptivity in supply networks: Building supply network theory using a complex adaptive systems perspective", Decision Sciences, Vol. 38 No. 4, pp. 547-571.

Patton, M. (2002), “Qualitative research and evaluation methods (3rd ed.)". Thousand Oaks, CA: Sage Publications.

Paulraj, A., Chen, I.J., and Chung, C.H. (2006), "The role of information technology in supply chain integration, International Journal of Information Systems and Change Management, Vol. 1 No. 2, pp. 202-219.

Peng, T. A., Lin, N., Martinez, V., and Yu, C. J. (2010), "Managing triads in a military avionics service maintenance network in Taiwan", International Journal of Operations and Production Management, Vol. 30 No. 4, pp. 398-422.

Phillips, R., (2003), Stakeholder legitimacy, Business Ethics Quarterly, Vol. 13 No. 1, pp. 2541.

Rahim, M. A. (2002), “Toward a theory of managing organizational conflict", International Journal of Conflict Management, Vol. 13 No. 3, pp. 206 -235.

Rais M and Sheoran A. (2015), "Scope of supply chain management in fruits and vegetables in India”, Journal of Food Processing and Technology, Vol. 6 No. 3, pp. 1-7. 
Reardon, T., Bellemare, M.F., and Zilberman, D. (2020), "How COVID-19 may disrupt food supply chains in developing countries," IFPRI book chapters, in: COVID-19 and global food security”, chapter 17, pp. 78-80, International Food Policy Research Institute (IFPRI).

Robertson, S. K. (2020 April 5), "Could social distancing create a long-term shift for the grocery industry"? The Globe and Mail. https://www.theglobeandmail.com/business/article-could-socialdistancing-create-a-long-term-shift-for-the-grocery/.

Rossetti, C., and Choi, T. Y. (2008), "Supply management under high goal incongruence: An empirical examination of disintermediation in the aerospace supply chain", Decision Sciences, Vol. 39 No. 3, pp. 507-540.

Singh, R. (2011), "Developing the framework for coordination in supply chain of SMEs", Business Process Management Journal, Vol. 17 No. 4, pp. 619-638.

Reich, J. W. (2006), “Three psychological principles of resilience in natural disasters”, Disaster Prevention Management, Vol. 15 No. 5, pp. 793-798.

Risen, J.L. and Chen, M.K. (2010), "How to study choice-induced attitude change: Strategies for fixing the free-choice paradigm", Social and Personality Psychology Compass, Vol. 4 No. 12, pp. 1151-1164.

Rusbult, C. E. and Van Lange, P. A. M. (2003), "Interdependence, interaction, and relationships", Annual Review of Psychology, Vol. 54, pp. 351-375.

Schipmann, C. and Qaim, M., (2011), "Modern food retailers and traditional markets in developing countries: comparing quality, prices, and competition strategies in Thailand", Applied Economic Perspectives and Policy, Vol. 33 No. 2, pp. 345-363.

Shareef, M. A., Dwivedi, Y. K., Wright, A., Kumar, V., (2021), "Lockdown and Sustainability: An Effective Model of Information and Communication Technology", Technological Forecasting \& Social Change, Vol. 165, pp. 120531.

Shareef, M. A., Dwivedi, Y. K., Kumar, V., Hughes, D.L., and Raman, R., (2020a), "Sustainable Supply Chain for Disaster Management: Structural Dynamics and Disruptive Risks, Annals of Operations Research, (In press, July, 2020), https://doi.org/10.1007/s10479-020-03708-3.

Shareef, M. A., Dwivedi, Y. K., Kumar, V., Mahmud, R., Hughes, D.L., and Kizgin, H., (2020b), "The Inherent Tensions within Sustainable Supply Chains: A Case Study from Bangladesh", Production Planning and Control, Vol. 31 No. 11-12, pp. 932-949.

Shareef, M. A., Dwivedi, Y. K., Mahmud, R., Wright, A., Rahman, M. M., Kizgin, H., and Rana, N. P. (2019), "Disaster Management in Bangladesh: Developing an Effective Emergency Supply Chain Network”, Annals of Operations Research, Vol. 283 No. 1-2, pp. 1463-1487. 
Shi, Q., Ding, X., Zuo, J., and Zillante, G.(2016), "Mobile internet based construction supply chain management: A critical review," Automation in Construction, vol. 72, pp. 143-154.

Silvestre, B. S. (2015), "Sustainable supply chain management in emerging economies: Environmental turbulence, institutional voids and sustainability trajectories", International Journal of Production Economics, Vol. 167 No. September, pp. 156-169.

Singh, S.; Kumar, R.; Panchal, R.; and Tiwari, M.K. (2020), "Impact of COVID-19 on logistics systems and disruptions in food supply chain", International Journal of Production Research, 116. https://doi.org/10.1080/00207543.2020.1792000.

Somashekhar, I. C., Raju, J.K., and Patil, H. (2014), “Agriculture Supply Chain Management: A Scenario in India”, Research Journal of Social Science \& Management, Vol. 4 No. 7, pp. 89-99.

Stephenson, M. (2005), "Making humanitarian relief networks more effective: operational coordination, trust and sense making”, Disasters, Vol. 29 No. 4, pp. 337-350.

Stock, J.R. (1997), “Applying theories from other fields to logistics”, International Journal of Physical Distribution and Logistics Management, Vol. 27 No. 9/10, pp. 515-539.

Surana, A., Kumara, S.R.T., Greaves, M., and Raghavan, U.N. (2005), "Supply-Chain Networks: A Complex Adaptive Systems Perspective”, International Journal of Production Research, Vol. 43 No. 20, pp. 4235-4265.

Tate, W., and Ellram, L. (2006), "Services spent management: Outsourcing/offshoring your services spent”, CAPS Focused Benchmarking Report, CAPS Research.

Twomey, D. (1995), "Inter-organizational conflict resolution: the effects of power and trust". Academy of Management Proceedings, 197-199.

Trienekens, J. H. (2011), “Agricultural value chains in developing countries: A framework for analysis”, International Food and Agribusiness Management Review, Vol. 14 No. 2, pp. 51-82.

Van de Vliert, E. and Kabanoff, B. (1990), “Toward theory-based measures of conflict management", Academy of Management Journal, Vol. 33 No. 1, pp. 199-209.

Wall, J. A., Jr. and Callister, R. R. (1995), “Conflict and its management", Journal of Management, Vol. 21 No. 3, pp. 515-558.

Weerakkody, V., Dwivedi, Y. K., Brooks, L., Williams, M. D. and Mwange, A. (2007), “Egovernment implementation in Zambia: contributing factors", Electronic government, an international journal, Vol. 4 No 4, pp. 484-508.

Williamson, O. E. (2008), "Outsourcing: Transaction cost economics and supply chain management”, Journal of Supply Chain Management, Vol. 44 No. 2, pp. 5-16. 
Wu, P.-J. and Chaipiyaphan, P. (2019), "Diagnosis of delivery vulnerability in a logistics system for logistics risk management", The International Journal of Logistics Management, Vol. 31 No. 1, pp. 43-58.

Wu, Z., Choi, T. Y., and Rungtusanatham, M. J. (2010), "Supplier-supplier relationships in buyer-supplier-supplier triads: Implications for supplier performance”, Journal of Operations Management, Vol. 28 No. 2, pp. 115-123.

Zaheer, A. and Bell, G. G. (2005), "Benefiting from network position: Firm capabilities, structural holes, and performance", Strategic Management Journal, Vol. 26 No. 9, pp. 809-825.

Zainudeen A., Samarajiva, R. and Sivapragasam, N. (2011), "CellBazaar, a Mobile-Based e Marketplace: Success Factors and Potential for Expansion”, Mobile Telephony Special Issue, Vol. 7 No. 3, pp. 61-76.

Zhang, X., Hu, L., Salimath, M., and Kuo, C-C. (2019), "Developing Evaluation Frameworks for Business Models in China's Rural Markets”, Sustainability, Vol. 11 No. 118, pp. 2-28. 